IZA DP No. 8259

Nurse Unions and Patient Outcomes

Arindrajit Dube

Ethan Kaplan

Owen Thompson

June 2014 


\title{
Nurse Unions and Patient Outcomes
}

\author{
Arindrajit Dube \\ University of Massachusetts Amherst \\ and IZA \\ Ethan Kaplan \\ University of Maryland College Park \\ Owen Thompson \\ University of Wisconsin Milwaukee
}
Discussion Paper No. 8259
June 2014

IZA
P.O. Box 7240
53072 Bonn
Germany

\author{
Phone: +49-228-3894-0 \\ Fax: +49-228-3894-180 \\ E-mail: iza@iza.org
}

\begin{abstract}
Any opinions expressed here are those of the author(s) and not those of IZA. Research published in this series may include views on policy, but the institute itself takes no institutional policy positions. The IZA research network is committed to the IZA Guiding Principles of Research Integrity.

The Institute for the Study of Labor (IZA) in Bonn is a local and virtual international research center and a place of communication between science, politics and business. IZA is an independent nonprofit organization supported by Deutsche Post Foundation. The center is associated with the University of Bonn and offers a stimulating research environment through its international network, workshops and conferences, data service, project support, research visits and doctoral program. IZA engages in (i) original and internationally competitive research in all fields of labor economics, (ii) development of policy concepts, and (iii) dissemination of research results and concepts to the interested public.
\end{abstract}

IZA Discussion Papers often represent preliminary work and are circulated to encourage discussion. Citation of such a paper should account for its provisional character. A revised version may be available directly from the author. 


\section{ABSTRACT}

\section{Nurse Unions and Patient Outcomes}

We estimate the impact of nurse unions on health care quality using patient discharge data and the universe of hospital unionizations in California between 1996 and 2005. We find that hospitals with a successful union election outperform hospitals with a failed election in 12 of 13 nurse sensitive patient outcomes measures. We also find that hospitals with a unionization drive are establishments with declining quality as measured by patient outcomes. When such declines are accounted for using hospital-specific trends, we find that unionized hospitals also outperform hospitals without any union election in the same 12 of 13 outcome measures. The timing of the quality improvement is consistent with a causal impact: the largest changes occur precisely in the year of unionization. The biggest improvements are found in the incidence of metabolic derangement, pulmonary failure, and central nervous system disorders such as depression and delusion, where the estimated changes are between $15 \%$ and $60 \%$ of the mean incidence for those measures. Dynamic estimates confirm that the improvements in health care outcomes occur within the first two years following nurse unionization.

JEL Classification: I12, J51

Keywords: $\quad$ unions, nurses, health care quality, hospitals

Corresponding author:

Arindrajit Dube

Department of Economics

Thompson Hall

University of Massachusetts Amherst

Amherst, MA 0100

USA

E-mail: adube@econs.umass.edu 


\section{Introduction}

Economists have long recognized the possibly contradictory effects of trade unions on product quality. The impact on quality is related to the broader question of unions' effect on workplace productivity. In their seminal contribution What do Unions Do?, Freeman and Medoff (1984) argued that increased "voice" could increase productivity through greater worker effort and lower turnover, as well as through increased information flows between management and labor. The increase in productivity may also stem from skill upgrading (Lewis 1986, Freeman and Medoff 1984), or greater capital intensity of production. Similar mechanisms could also lead to an increase in product quality. In contrast, product quality or productivity may suffer from restrictive union-imposed workplace rules, reduced investment, and weaker employer incentives to screen for better workers (Card 1996, Lee 1978, Wessels 1994).

Overall, the limited evidence on the topic has been mixed. As part of a 20 year retrospective of What do Unions Do? Hirsch (2004) reviewed the literature to date and argued that on net there was little clear evidence of the positive impact of unions on productivity postulated by Freeman and Medoff (1984). However, the causal relationship between labor relations and worker productivity has been difficult to discern due to the dual challenge of measuring productivity and isolating plausibly exogenous variation in unionization.

Within the past decade, there have been a number of papers looking at labor relations as a potential determinant of product quality. Krueger and Mas (2004) estimate the impacts of labor strife on production error rates in Firestone Tires; Mas (2008) looks at the impact of labor strife on machine production quality; and Mas (2006) looks at the impact of the outcome of union wage bargaining on police apprehensions. In contrast to our work, these papers do not specifically estimate the impact on quality stemming from union presence.

In this paper, we estimate the impact of the presence of nursing unions on a host of patient outcomes deemed as sensitive to nurse performance in the medical nursing literature. We use nurse union election data matched to a panel of administrative patient outcome data from the universe of hospitals which report to the state of California. Nurse unions are a natural place to look for unionization impacts on product quality for two reasons. First, different from most occupations, nurses work at employers who are required to report detailed outcome measures. Thus, there is reliable data from which to measure the impact of nurse unionization on quality, and we specifically use 13 such nurse-sensitive outcomes identified in a seminal article in the New England Journal of 
Medicine by Needleman et al. (2002). Second, nurses are one of the few occupations which has seen strong growth of unionization in the past few decades. They are therefore one of the few occupations from which estimating the impact of unionization on productivity is feasible. Finally, the impact of unionization on care quality is interesting for its own sake due to its relevance for public health.

We use a difference-in-difference research design, and our preferred strategy compares changes in outcomes at hospitals undergoing successful unionization with changes where the effort fails. Pooling across standardized outcomes, we find that prior to the election, hospitals with successful unionizations had similar trends in outcomes as hospitals with failed unionizations. However, after the recognition election, unionizing hospitals perform statistically significantly and substantially better than hospitals where the union loses the election. In addition, unionizing hospitals perform better relative to the full sample of control hospitals in California when we account for hospital-specific linear or quadratic trends. We see particularly large impacts on metabolic derangement, pulmonary failure, and central nervous system disorders. Overall, our effects suggest that unionization leads to a decline of $5.6 \%$ of a standard deviation in the average of our thirteen measures relative to a sample of all hospitals and $6.1 \%$ of a standard deviation relative to a sample of hospitals with unsuccessful unionization attempt. The effects on metabolic derrangement and pulmonary failure are over $15 \%$ of a standard deviation, and the effects are over $40 \%$ for central nervous system disorders. The timing of the changes further supports a causal interpretation of our findings: the largest improvements occur during the year of the unionization, and the second largest during the following year.

Our paper relates to a small number of recent studies which have attempted to estimate the impact of nurse unions on quality of care. Gruber and Kleiner (2010) uses an event study methodology to estimate the impact of nurse strikes on mortality, and find that the average strike increases mortality by over $18 \%$. However, strike days are a very small portion of the total days of employment for a unionized workforce and therefore looking at the impact of strikes is not sufficient for understanding the quality impact of nurse unionization. Similar to this paper, Ash and Seago (2005) estimate the impact of nurse unions on patient health, specifically considering mortality due to cardiac arrest. They find that patients in hospitals where nurses are unionized are $5.5 \%$ less likely to die from a myocardial infarction. Although they use a variety of methods to account for the selectivity of unionization, their identification is purely cross-sectional. Given the non-random nature of unionization documented here, it is not clear whether these estimates necessarily reflect a causal impact of unionization.

The paper most similar to ours is by Sojourner et al. (2012) which uses a regression discontinuity 
design to look at patient quality measures in nursing homes following an unionization event. Different from our paper, they find no impact of unionization on care quality though they do find an employment decline from which they argue for increased productivity. While our conclusions on quality do differ from those of Sojourner et al., there are a number of plausible explanations for these differences. Most importantly, the patient profiles and basic nature of nursing tasks in the convalescent settings studied by Sojourner et al. are substantively different than those in the general hospital settings that we study here. Additionally, Sojourner et al. work with a larger, national sample of unionizations and are therefore able to implement a regression discontinuity research design, while our smaller CA sample is only amenable to the difference-in-difference approach that we adopt. While the timing of our effects, their prevalence across a large number of nurse-sensitive outcomes, and our use of multiple comparison groups strongly points to a causal interpretation, it is possible that we are identifying the average of heterogeneous treatment effects across unions of different strengths. This is because we do not have the statistical power to limit our sample only to close elections. Lee and Mas (2010) find evidence of differential impacts in close versus lop-sided elections. Finally, we analyze a broader and arguably higher quality set of patient outcome measures than Sojourner et al. Given that any or all of these factors could be expected to impact the findings, we view our work as reconcilable and complimentary to that of Sojourner et al.

The remainder of the paper is structured as follows. In section 2 , we describe the data on patient outcomes and unionization. Section 3 outlines our estimation strategy. In section 4 , we present our main results. Section 5 provides additional interpretation of our results, and section 6 concludes.

\section{Data}

Our data on patient outcomes come from the Patient Discharge Database (PDD) maintained by the Office of Statewide Health Planning and Development (OSHPD) in California. The PDD is a confidential dataset covering all individuals discharged from regulated California hospitals between 1988 and 2005.

The PDD contains information on a large number of patient diagnoses. To ensure that our selection of patient outcome measures was not inappropriately influenced by the corresponding end results, we pre-committed to extracting only 13 diagnosis measures which have been deemed nurse sensitive in the nursing literature. In particular, we followed Needleman et al. (2002), a seminal article in the nurse quality literature with 1861 citations. We used the measures that they reviewed with the exception of Length of Stay, which is not a patient welfare measure. We then extracted only 
these 13 outcomes from the PDD microdata and we report results for all 13 below.

The specific patient outcome measures and corresponding acronyms are as follows: Urinary Tract Infection (UTI), Pressure Ulcer (PRU), Hospital Acquired Pneumonia (HAP), Hospital Acquired Sepsis (HAS), Shock or Cardiac Arrest (SCA), Upper Gastrointestinal Bleeding (UGB), Metabolic Derangement (MDB), Deep Vein Thrombosis (DVT), Central Nervous System disorder (CNS), Wound Infection (WIN), Failure To Rescue (FTR), and In-Hospital Death (IHD). Each of these measures is constructed using the ICD9 diagnostic codes described in Needleman et al. (1992). We received permission from OSHPD to extract the counts of these outcomes at the hospital level, disaggregated by patient demographic categories (race, age and gender), the Major Diagnostic Code for admission, and the month of admission.

A distinct strength of the PDD data is that from 1996 forward, it contains counts for each outcome that were present on admission. In most of our results, we report prevalence of these outcomes which were obtained in the hospital (i.e. not present on admission - NPOA). We collapse our data to the hospital-year level, so that our working dataset is an annual panel of hospitals from 1996 to 2005 , with incidence of the 13 conditions that were not present on admission, along with the share of patients by gender, 4 race and ethnicity categories, 8 age categories, 25 Major Diagnostic Codes, and present-on-admission levels for each of the outcomes.

Using the total number of admitted patients, we express each of our 13 hospital-year level outcome measures in incidence rate per thousand patients. Additionally, we construct an aggregate measure of disease incidence across outcomes for each hospital-year. To do so, we first standardize each specific measure by subtracting its mean and dividing by the standard deviation taken over the entire panel of hospitals. We then take the simple mean of these standardized outcomes across all 13 measures. That is, letting $h$ index hospitals, $t$ index time, and $j$ index outcomes so that $y_{h t}^{j}$ corresponds to outcome $j$ at hospital $h$ at time $t$, our combined measure is defined as

$$
A l l_{h t}=\frac{1}{13} \sum_{j=1}^{13} z_{h t}^{j}
$$

where

$$
z_{h t}^{j}=\frac{y_{h t}^{j}-\frac{\sum_{h, t} y_{h t}^{j}}{N}}{\sqrt{\frac{\sum\left(y_{h t}^{j}-\sum_{h, t} y_{h t}^{j}\right)^{2}}{N}}}
$$

To our patient outcome data, we merge information on the universe of NLRB conducted union 
representation elections for bargaining units that included registered nurses in California occurring over the sample period. While the majority of the information in our election data originated in monthly NLRB Election Reports, these reports contain only broad industry and bargaining unit classifications, and it is often impossible to differentiate RN unionization elections from elections involving, for instance, nursing assistants or a hospital's clerical, food service or janitorial workers. To gain more precise information on the categories of workers within hospitals that were included in each NLRB election, we purchased supplemental data from a private analytics firm, the Bureau of National Affairs (BNA) Employment and Labor Division. The BNA data was compiled through systematic searches of periodicals and court documents and specifically identifies which certification elections within hospitals contained RNs. ${ }^{1}$

We then hand-matched hospitals that had RN elections to the corresponding patient discharge data using the municipality where the hospital was located and the hospital's commercial name and/or parent company. This procedure yielded matches for $50 \mathrm{RN}$ certification elections, 39 of which resulted in the certification of a union and 11 of which did not. ${ }^{2}$

Figure A1 of the appendix displays a histogram of the years in which our sample of unionization elections took place. The figure indicates that elections took place at relatively uniform time intervals over the sample period, allowing us to reliably discern time effects from the impact of unionization. Figure A2 displays the histogram of vote shares in favor of unionization. While the limited number of union losses makes our sample unsuitable for a regression discontinuity research design, Figure A2 does indicate that a majority of the successful elections in our sample were at least reasonably close, and only in relatively few cases did the union vote share exceed $65 \%$. While not a substitute for a full analysis based upon the discontinuity in assignment of union status occurring at $50 \%$ of the vote share, the fact that most union victories are relatively close in vote share to union losses increases the likelihood that our difference-in-difference estimates presented below reflect the causal impact of unionization as opposed to trends in hospitals associated with union election victories.

\footnotetext{
${ }^{1}$ In all but three instances the bargaining units containing RNs consisted exclusively of RNs. In the remaining three instances RNs were grouped with other skilled hospital staff, such as pharmacists, dieticians and lab technicians. Because we are working with a relatively limited set of elections, we retain these cases in our sample, but the results we present below are not substantively changed if they are excluded, and are available upon request.

${ }^{2}$ In two instances a hospital had a failed RN certification election followed by a successful election at a later date. We retain these cases and categorize them as union wins after the date of the successful election, but our results are not substantively changed if we instead classify them as union losses in the interim period or exclude them. Also note that while our patient data is restricted to 1996 through 2005, our dynamic specifications presented below utilize data from 16 elections which took place outside of this range to identify leads and lags of unionization effects, and the quoted totals include these 16 elections.
} 


\section{Empirical Specification}

We employ a difference-in-difference research design using two sets of control hospitals. Our preferred control group consists of hospitals that experience a failed unionization attempt. We believe that this control group better accounts for unobserved confounders that may be correlated with unionization status. Our second control group consists of all hospitals in the OSHPD data.

For each of these samples, we utilize two main specifications. In the first specification, we regress the outcome measure $j$ at time $t$ in hospital $h$, denoted by $y_{h t}^{j}$, onto the union status of the hospital's RNs, hospital fixed effects, year effects, and a vector of controls variables:

$$
y_{h t}^{j}=\alpha+\beta \text { Union }_{h t}+X_{h t} \Gamma+D_{h}+I_{t}+\epsilon_{h t}
$$

where Union $_{h t}$ is a dummy which takes on a value of 1 when there is an RN union present, $D_{h}$ is a set of hospital dummies, $I_{t}$ is a set of year dummies, and $X_{h t}$ is a vector of controls that contains the percentage of patients discharged in each year by gender, 4 race and ethnicity categories, 8 age categories, 25 Major Diagnostic Codes, and present-on-admission levels for each of the outcomes.

Our second specification is similar to Equation 3, but additionally allows for a hospital-specific trend, $\theta_{h}$ :

$$
y_{h t}^{j}=\alpha+\beta \text { Union }_{h t}+X_{h t} \Gamma+D_{h}+I_{t}+\theta_{h} t+\epsilon_{h t}
$$

Finally, to examine the timing of the impact, we also estimate dynamic specifications where we include leads and lags in union presence as regressors:

$$
y_{h t}^{j}=\alpha+\sum_{k=-F}^{L} \beta_{k} \text { Union }_{h t+k}+X_{h t} \Gamma+D_{h}+I_{t}+\theta_{h} t+\epsilon_{h t}
$$

All other regressions reported are modifications of these basic specifications, and are discussed below as neccesary

\section{Main Results}

In this section, we present descriptive statistics by unionization status and our baseline difference- 
in-difference estimates, as well as dynamic evidence and a variety of robustness checks.

\subsection{Descriptive Statistics on Hospitals}

We consider three types of hospitals in our sample. Those that do not have nurse union elections during the sample period, those who win union elections during the sample period and those who only lose union elections during the sample period. This leaves us with a total of 616 hospitals in our sample with no elections, 39 with union wins, and 11 with failed unionization drives.

We present descriptive statistics about our three samples of hospitals in Table 1. The average patient in a hospital with a nurse election victory during our sample is almost 6 percentage points more likely to be white than a patient in a hospital with no union elections and is approximately 5 percentage points less likely to be white than the average patient in a hospital with a failed union election attempt and no successful attempts. In addition, hospitals with union wins are more likely to have African-American and Latino patients than hospitals with failed union elections but are less likely to have patients of Latino and African-American origin than hospitals without any union elections during the sample period. This in part reflects that hospitals with union victories are more likely to be in wealthy urban areas than hospitals without union elections but are less urban and less wealthy than hospitals with failed union elections.

There are small differences in the gender composition of patients across the three groups, with hospitals with a union election but no election wins having the highest percentage of female patients and hospitals without union elections having the lowest. However, the total gap between the no election sample and the union election loss sample is only 1.1 percentage points. Differences in age composition across hospital types are larger than gender differences. The hospitals with union losses are slightly more than 4 percentage points more likely to have a patient over 65 years of age than the hospitals with union wins. Approximately $44 \%$ of patient admits are above 65 years of age. Only $37 \%$ of the patient admits were over 65 in the non-election hospitals. Interestingly, the hospitals with union victories were the most likely to have patients under 18. Though hospitals with union wins had $24 \%$ of patients under 18 and hospitals with no elections were similar with $23 \%$, hospitals with union losses and no wins had only $19 \%$ of their admitted patients below the age of 18 .

Differences in outcomes across our three samples of hospitals are heterogeneous according to measure. In all but two of our 13 measures (pressure ulcers and hospital acquired sepsis), the no-election hospitals have the lowest incidence rates. Also, in all but two of our measures (metabolic 
derangement and wound infection rates), incidence rates are higher in hospitals which unionize than in hospitals with a failed union election. However, for some of the measures, the incidence rates are quite similar between the hospitals which successfully unionize and those which do not; for other measures, they differ substantially. For example, the in-hospital death rate differs by only 1 out of every 100,000 patients between the unionizing and failed union election hospitals. By contrast, the in-hospital death rate differs by 59 out of 100,000 between the failed union election sample and the no election sample. In one out of the three measures where unionization is estimated to have a particularly large impact (metabolic derrangement), the incidence rates are in between those of the two control groups: the full sample and the sample of hospitals where unions lose elections. However, for gastrointestinal bleeding, incidences differ by only 35 patients out of every 100,000 between the failed union election sample and no election sample but differ by 307 per 100,000 patients between the failed union election sample and the no election sample. Overall, in 5 of our 13 measures, the incidence rates in the failed union election sample are closer to those in the unionizing sample than to those in the non-election sample.

The reported differences across our three groups of hospitals warrants some caution. However, as we will show in the following sections, there seem to be no difference in pre-existing trends between our sample of union wins and our full sample conditional on trends nor are there differences in trends between our sample of union wins and our sample of union losses.

\subsection{Baseline Results}

We now show our baseline estimates of the impact of nurse unionization on nurse sensitive patient outcomes. Our main findings are that unionizing hospitals in California during the 1990s and 2000s are hospitals in decline relative to the average hospital, but that hospitals which successfully unionize perform better afterward relative to those who unsuccessfully unionize, and also outperform the sample of hospitals with no unionization attempt once we account for linear hospital-specific time trends.

In Table 2, we show estimates for models 1 and 2 (without and with hospital-specific linear time trends respectively) for both the full sample and the sample of hospitals with union elections. The outcome measures used in Table 2 are in terms of incidence per thousand patients, but to aid in the visual interpretation of the results, Figure 1 converts the coefficients from columns 2 and 4 to percent changes using the sample-wide mean of each outcome, and plots these along with the associated $90 \%$ confidence intervals. The full sample is almost ten times the size of the election sample, with nearly 5,000 observations compared to 465 in the election sample. In the full sample, without controlling for 
hospital trends, hospitals which unionize have reductions in 6 of 13 nurse sensitive measures. In the other measures, there are increases in outcome prevalence. Only two of the measures are statistically significant at conventional levels: in hospital death (IHD) and failure to rescue (FTR). When we pool across the outcomes using standardized measures, our aggregate index of nurse sensitive health quality shows a very small increase in disease prevalence.

However, we may worry that the parallel trends assumption in the first specification does not hold across hospitals with and without unions. Consistent with this evidence, if we add linear trends to this model (specification 2), we observe qualitatively different findings. While we only have one prevalence reduction which is significant at a 5\% level (central nervous system disorders) and one other at a $10 \%$ level (metabolic derangement), we now find that estimates for 12 out of 13 of our measures are negative. If the sign of the impact on these different outcome measures were independently distributed with a $50 \%$ probability, this would happen by random chance with a probability of less than $0.2 \%$. Notably, when we pool across the standardized outcomes, our aggregate index shows a drop of $5.6 \%$ of a standard deviation and is significant at below a $3 \%$ level of significance.

Turning to the sample of hospitals with union recognition elections, our specification without trends shows that there is a decline in the prevalence of all of our outcome measures after unionization in comparison with hospitals with failed unionization attempts. Moreover, five of these measures show significant declines at the $5 \%$ level. If the sign on the impact of these measures were independently distributed, this would happen by random chance with less than a $0.03 \%$ probability. Additionally, seven of the 13 measures show significant declines at a $10 \%$ level of significant, which would happen by random chance with a probability of less than $0.01 \%$. When pooling across measures, our aggregate index falls by $9.1 \%$ of a standard deviation and is significantly different from zero at a $1 \%$ level of significance.

Adding linear trends to this specification produces qualitatively similar findings, though the magnitudes of the estimates are typically smaller. The overall standardized aggregate shows a $6.1 \%$ of a standard deviation decline following unionization, and this impact is statistically significant at the $5 \%$ level. Of the 13 outcomes, 12 show a reduction; the only measure with a positive coefficient, upper gastrointestinal bleeding, has an estimated effect that is nearly identical to zero $(0.0011)$ and with standard errors more than 20 times the coefficient size. Similar to the full sample with hospital-specific trends, there are only two measures that are significant at the $10 \%$ level: central nervous system disorders and metabolic derangement. 
As noted, we find particularly large and precise effects for metabolic derangement and central nervous system disorders. ${ }^{3}$ Metabolic derangement includes ICD 9 codes 250.10, 250.11 and 998.0. Included in these diagnosis categories are sugar shock from diabetes as well as post-operative metabolic shock. Using our baseline estimates with trends, the number of patients with metabolic derangement drops by 13 per 1,000 patients in the election sample and 15 per 1,000 patients in the full sample. These represent drops of $17 \%$ and $21 \%$ of the mean number of patients with metabolic derangement in the sample of hospitals with union victories. Central nervous system disorders include ICD 9 codes 780.0, 293.0, 298.2, and 309.1-309.9. This category includes delusion, disorientation, and depression. The drop in incidence for central nervous system disorders are even more substantial than those for metabolic derangement, exceeding $50 \%$ in both the full sample and the election sample.

In most specifications, we do not find effects on the most serious conditions such as in-hospital death and failure to rescue. However, we note that our power for these measures is more limited because they are less prevalent (see Table 1). Furthermore, although we utilize a pre-specified set of outcomes to minimize multiple-testing bias, we do not consider all of them to be equal when it comes to the sensitivity to nursing quality. Therefore, we find it reassuring that where we see our strongest effects are on measures where we think the role of nurses is more likely critical.

Overall, these findings suggest that unionizing hospitals in California during the 1990s and 2000s are hospitals in decline relative to the average hospital. However, hospitals which successfully unionize perform better afterward relative to those with failed unionizations, and relative to the full sample after accounting for hospital specific trends.

\subsection{Dynamic Evidence}

We now present dynamic evidence on the timing of improvements in health care outcomes following unionization. For simplicity, we restrict our analysis to the aggregate outcome measure. Thus, the coefficients should be interpreted as effects of unionization measured in averages of standard deviations. We include two leads and four lags in union status, along with the contemporaneous union variable. The omitted category, then, is 3 or more years prior to the election; and the fourth lag captures the effect four or more years after the election. We again show four specifications: with and without linear hospital-level trends, and full and election samples.

The numerical results are reported in Table 3, while in Figure 2 we plot the running sum of the

\footnotetext{
${ }^{3}$ While the percent reductions in pulmonary failure were also quite large in magnitude, they were less precise and in many cases statistically insignificant, so we focus our discussion here on MDB and CNS.
} 
coefficients beginning with the 2 year lead, which represents the "impulse response" in the mean outcome level compared to the baseline period of 3 or more years prior to the election. Figure 2 shows two sets of 95 percent confidence intervals (CI's) associated with two different baselines. The first, lighter shaded, confidence interval is for the response at year $t$ relative to the baseline of years -3 and earlier. The change between the baseline and year $t$ is statistically indistinguishable from zero if the lighter shaded 95 percent CI for year $t$ does not contain zero. The specification with the full sample and without hospital trends shows changes between the baseline and years -2 and -1 that are positive and statistically significant. This confirms that unionizations tend to to occur more in hospitals undergoing quality declines. In contrast, the other three specifications do not show statistically significant or medically sizable changes between the baseline and years -2 and -1 . Better comparison groups or parametric trend controls account for these pre-existing trends, and these 3 specifications show stable relative outcomes prior to the election. The same conclusion is reached by looking at the individual leading coefficients in Table 3. Overall, the leading effects falsification test suggests that specifications 2, 3 and 4 are preferred based on how well they are able to match pre-existing trends in the treatment and control groups.

Figure 2 provides visual evidence that in all three of these preferred specifications, there is an unmistakable drop in the aggregate outcome during the year of the union election win. Table 3 documents that the contemporaneous coefficient is statistically significant in all three specifications: it is also the largest coefficient in magnitude in these three cases. In contrast, the specification without trends in the full sample does not indicate a substantial change following the election.

To statistically test for short and long term changes following unionization, we also report a second, darker shaded, confidence interval in Figure 2 for the effect since year -1 just prior to the election. The null hypothesis that the changes since year -1 until year $t$ is statistically indistinguishable from zero is rejected if the darker 95 percent $\mathrm{CI}$ in year $t$ does not contain the point estimate associated with year -1 . We can see from the figure that in models 2,3 and 4 , the effects are statistically significant at the 5 percent level during years 0 and 1 . For models 2 and 3 , the effects remain significant throughout the post election period, while in model 4 (the election sample with trends) the later lags lose precision.

Table 3 provides the numerical counterpart to the visual evidence: the "short run" impact through the year after the election is quite substantial, ranging between -0.085 and -0.121 across the three specifications; the estimates are statistically significant at the five percent level. We do note that we 
see a statistically significant above-mean incidence in unionizing hospitals relative to the others in the full sample two years before the election. However, controlling for hospital-specific linear trends elimiminates this pre-effect statistically and substantively. No such pre-effect exists in the hospital election sample with or without trends. Estimates for longer run impacts (through the 4th year or later) range between -0.097 and -0.167 and are unsurprisingly less precise; however, they continue to be statistically significant at the 5 percent level in 2 out of the 3 preferred specifications. In all three preferred specifications, we see no indication that the gains in quality were temporary: the longer term estimates appear to be larger than the estimates from the contemporary specification.

Overall, the evidence strongly points to a clear and immediate improvement in the average quality indicator following a successful union election, which appears to grow somewhat over time. Moreover, the dynamic evidence also shows that the one specification without a measured union effect is also the only one which fails the falsification test for pre-existing trends.

Without the explicit inclusion of lags in unionization, a delayed effect of union presence can be mistaken for a hospital trend, thereby attenuating the estimate of the union's impact. In our dynamic specifications, the inclusion of the lags and leads in unionization implies that the hospital-specific linear trends are largely identified using data from 3 or more years before, or 5 or more years after, the union election. The estimated hospital trends in such a model are, therefore, more likely to reflect pre-existing trends unaffected by the treatment itself. This suggests that we can compare the dynamic and contemporaneous specifications to assess whether the trends are partly absorbing the dynamic treatment effect. Since there were, on average, 3.2 post-election years in our sample (excluding the year of the election), we should roughly expect the estimated effect through year 3 in the dynamic specifications to be comparable to the estimates from the contemporaneous specifications. The three-year-out effects can be calculated from Table 3, and for the preferred models 2, 3 and 4, are $-0.152,-0.107$, and -0.086 , respectively. These compare to the estimates from Table 2 which are $-0.056,-0.091$, and -0.061 . We find that the estimates from models with linear trends (models 2 and 4) are sizably larger in magnitude when lags are included. Model 3, which does not include trends, is the least affected by the inclusion of lags. These results suggest that, if anything, the estimates from the contemporaneous specifications may be somewhat understated due to the presence of lagged effects. We show additional evidence on this question in section 4.5, where we separately estimate post-unionization trends. 


\subsection{Patient characteristics and case load}

One possible concern about our results is that they reflect changes in the case mix or case load which occurred at the time of unionization. We test for this by regressing demographic measures and number of patients on hospital fixed effects, time fixed effects, other demographic variables and a union dummy as we did in Table 2. As before, we present results for our four main specifications: with and without hospital trends and in the full sample as well as the election sample. The particular measures that we use are the ones we initially collected: the log of the number of patients, the percentage of patients who are female, the percentage of patients who are non-white, the percentage of patients under 18, and the percentage of patients over 65 .

Results are shown in Table 4. None of the 20 coefficients are different from zero at even a $10 \%$ level of statistical significance. Two of the measures (log total patients and percentage of patients under 18) are negative in all 4 specifications. However, the coefficients are rather small for the under 18 year olds. The coefficients on log total patients, though never significant, do show a roughly $2 \%$ decline in number of patients. We will return to this point when we discuss interpretations of our results in Section 5 .

\subsection{Robustness Checks}

Tables 5 and 6 show a number of robustness checks to our main results. The first of these tables, Table 5, looks at robustness to the window over which the results are estimated. In particular, we are concerned that, particularly since hospitals which face union elections are hospitals in decline, the relationship between covariates and outcomes may be changing over time, possibly biasing our estimates. To address this issue, we estimate our effects over shorter windows where the covariates are less likely to be changing. Again, we focus on our aggregate measure of incidence which is expressed in averages of standard deviations. We show the results here for our preferred specification with hospital-specific trends.

In Panel A, we include only 2, 4, or 6 years of data prior to the election in hospitals with successful unionization, but continue to use the full panel of data from our control hospitals. These restrictions allow us to check the robustness of our findings to alternative pre-unionization baselines in the levels and trends in the outcomes.

We find that the results are largely similar after the omission of years before the election event. The election sample is more robust to excluding pre-election periods, probably because the pre-periods 
are more similar between the failed and successful unionization attempts than they are between either of these groups and the non-election hospitals. By far, the estimate that is lowest in magnitude is the 2 year window in the full sample, where the coefficient drops to -0.032 and is not significant at conventioanl levels. All the other estimates, across the full sample and the election sample, are -0.049 or below and significant at least a $10 \%$ level.

In Panel B, we focus on the length of the post-intervention period. Here we include only 2,4 or 6 years of data, respectively, from the post election period in hospitals with succesfull unionizations. As before, we continue to use the full panel of data from our control hospitals. We find that results for the aggregate measure of nurse-sensitive outcomes are broadly robust to the length of the post-unionization period. In the election sample, the coefficient estimate drops to slightly below -0.05 in magnitude and is not significant at a $10 \%$ level for the two year window. For the full sample, the drops are somewhat larger in magnitude and there isn't a monotonic relation betwen the number of years included and the size of the coefficient. The lowest estimated effect is -0.035 and is not significant at a $10 \%$ level. However, the two and six year samples are both statistically significant at a $10 \%$ level or lower. Overall, these results are consistent with our dynamic evidence in Table 3 , which shows a clear fall in the prevalence of the outcomes at the time of unionizaton, followed by some additional reductions afterwards.

In Table 6, we show that our results are robust to how we control for trends, how we control for the timing of elections and whether we control for the outcome prevalence upon admissions. We again break down our columns into results on the full sample and results on the election sample. Our first specification estimates the impact of unionization controling for the effect of any elections, successful or otherwise. In particular, we introduce a dummy that takes on the value of one after a union election and zero otherwise. Therefore, in this specification, our estimates are relative to election losses after the elections occur. The estimates of the union win effect are larger in magnitude in both the full sample and the election sample. Though the standard errors in the election sample rise due to colinearity between the post election dummy and the union win dummy, the number of measures significant at a $10 \%$ level or less rises from two to four relative to the baseline estimates. Moreover, the coefficient on the impact on the overall index of quality increases by around a third. The changes to the full sample are more stark. Even though, due again to colinearity the standard errors are uniformly larger, two measures in particular go up strongly in magnitude and become highly significant: deep vein thrombosis, and shock and cardiac arrest rates. Though the two measures 
with significant coefficients in the baseline trends model in the full sample lose significance, in obth cases, the coefficients rise in magnitude.The estimate for the aggregate measure of quality increases in magnitude by around two-thirds, and looks much more similar in this specification to the results from the election sample. This is sensible since we are now largely comparing election wins to election losses (by controlling for elections) even in the full sample.

In columns 2 and 5 of Table 6 , we control for quadratic trends to see whether our results are robust to other ways of controlling for hospital level trends. Our results are identical in both the full sample and the election sample to 2 digits and in most cases, to three digits. It is reassuring that variations in the parametric form of hospital specific trends changes the results to only a minimal extent.

As we discussed in the context of dynamic specifications, with lagged treatment effects, the estimates for the hospital specific trend may be affected by the unionization itself. To ensure that hospital-specific trends represent pre-existing trends rather than trends after unionization, columns 3 and 6 include controls for time trends before and after unionization in addition to hospital-specific linear trends. Allowing additional pre- and post-unionization trends increases the magnitude of our estimates from -0.056 to -0.059 in the full sample and -0.061 to -0.075 in the election sample. In both cases, the standard errors increase substantially due to greater colinearity of the treatment effect with the controls. The election sample estimate remains significant at the $10 \%$ level while the full sample estimate drops slightly below the $10 \%$ significant level. Moreover, the reported coefficent on the union dummy does not account for the effect on the trend itself, and only accounts for the immediate impact in the election year. When we evaluate the average effect inclusive of the impact on trends using the mean length of the post-election period (3.2), we find that the estimate (standard errors) for the aggregate outcome is -.106 (.040) in the full sample, and -.093 (.045) in the election sample ${ }^{4}$ In both samples, average cumulative effects over the mean length of the post period are statistically significant at $5 \%$ levels. These estimates are similar to our evidence from the dynamic specifications. They indicate that the presence of lagged effects may, if anything, lead to a smaller estimate in specifications with linear trends.

Finally, in columns 4 and 8, we assess the concern that the apparent reduction in disease incidence may be due to better screening of conditions during admission, rather than actual changes in outcomes

\footnotetext{
${ }^{4}$ See McCrary 2007 for more on interpreting coefficients with linear trend breaks.
} 
during the hospital stay. For this reason, we remove from our control set the prevalence of these outcomes among patients during admission. Contrary to that hypothesis, we find that the magnitude of the fall in incidence rises in almost all specifications both in the full sample and in the election sample. The coefficient for urinary tract infections becomes statistically significant at a $10 \%$ level or less in both samples. Moreover, the coefficients for pressure ulcers and deep vein thrombosis become statistically significant at a $10 \%$ or lower in the elections sample. Our overall measure of outcome quality declines by over $50 \%$ in both samples to -0.084 in the full sample and -0.108 in the election sample.

\section{$5 \quad$ Interpretations}

In this section, we consider various explanations for our findings of improved quality outcomes following unionization. First, it is possible that our results do not reflect the causal effect of unions but rather endogeneity in the timing of unionization. In particular, a temporary drop in health care quality may induce a union organizing drive; subsequently, conditions may improve leading to a natural recovery in quality without unionization itself playing any role. Consistent with this endogeneity explanation, we do, in fact, see that unionizations occur in hospitals experiencing quality decline. This is evident from model 1 in Table 3 where the estimates use all hospitals and do not control for linear hospital trends. However, contrary to the endogeneity explanation, we do not see relative quality decline in our preferred specifications using the election sample, or the full sample with hospital trends. Moreover, we only see improvement after an election in the hospitals where the union wins the election. Accounting for an "election effect" by adding a separate election dummy does not attenuate the findings: instead the estimates from that specification are actually larger in magnitude. The findings from the election sample suggests that successfully unionizing hospitals would probably not have recovered in the absence of union formation.

A second possibility is that unionization leads to a shift in patient selection. If patients or doctors of patients know about the unionization and think it could negatively impact care, sicker patients could be directed towards other hospitals. Alternatively, unionized nurses could transfer sicker patients to other hospitals at triage. This could lower staffing ratios but even more importantly, lead to healthier patients being admitted and thus patients who are less likely to acquire diseases and encounter problems when recovering in the hospital. Although we do find a statistically insignificant but consistent reduction in number of patient case load after unionization, we do not find any evidence 
of a shift in patient demographics, including age. Thus we do not think that selection of patients is likely to explain our results on patient outcomes.

A third possible mechanism for a reduction in outcome measures is a change in reporting. We estimate the impact of unionization on outcomes that were not present upon admission. However, it is possible that unionization leads to a change in the probability of detection of these conditions during admission. One variant of this argument is that hospitals start screening more diligently when admitting patients. In this case, there would be a decrease, due to changes in reporting, of conditions not present at admission due to an increase in reporting of conditions at admission. An opposite explanation is that conditions increasingly go unreported after unionization. However, as we showed in Table 6, our qualitative results hold with or without controls for the prevalence of these conditions on admission. Therefore, we do not think that our results merely reflect changes in reporting standards after unionization.

A fourth possible explanation is that after unionization, conditions increasingly go unreported and thus there is an apparent downturn in prevalence of conditions not present upon admissions. However, since this reporting is largely done by doctor diagnosis (different from triage), it is unlikely that this would happen without collusion between doctors and nurses. We think this is unlikely to have happened at any noticeable scale.

Since our findings appear to be causal effects of unionization (as opposed to statistical artifacts), it is useful to consider various channels through which this may occur. We note at the outset that we are not able to test for the importance of these specific potential channels, but it would be valuable to do so in future work. Broadly speaking, unionization may improve patient health outcomes through (1) increased wages and morale (2) changes in nurse staffing ratios, and (3) increased capital intensity.

To the extent unions are able to raise nurse wages, this may improve quality of care through increasing effort, reducing turnover, and possibly increasing morale. ${ }^{5}$ This is the standard mechanism through which unionization has been hypothesized to improve production quality and is similar to the one considered in Mas (2006). Numerous cross-sectional studies of the nursing sector have found a positive union wage premium (Hirsch and Schumacher 1998, Spetz et al. 2010) and although marginal unionizations in manufacturing seem to have had no impact upon average wages in recent years (DiNardo and Lee 2004), more recent evidence by Frandsen (2011) suggests union wins are

\footnotetext{
${ }^{5}$ The nursing labor market has often been characterized as being monopsonistic, which highlights the possible role of easing recruitment and retention through better compensation. However, we note that recent evidence by Matsudaira (forthcoming) raises some questions about the simple monopsony explanation.
} 
associated with sizable increases at the bottom of the earning distribution coupled with earnings losses at the top. Moreover, relevant to our findings here, other recent work suggests that victory by unions with strong support may in fact have sizable impacts (Lee and Mas, 2010).

Assuming that nurse unionization does indeed raise wages, there is evidence that such increaes frequently translate into improved nurse retention and patient outcomes. For instance, Schumacher (1997) and Saego et al. (2011) both document higher nurse retention in higher paying and unionized hospitals, while recent work by Propper and Van Reenen (2010) found that low nurse wages relative to local labor markets significantly increased patient mortality in British hospitals. A related mechanism is that winning a union election may improve nurse morale. In addition to morale improvements related to increased wages, nurses may feel they have more voice on the job (Freeman and Medoff, 1984) or generally better about the work environment and that may itself improve work performance. Since our dynamic estimates show contemporaneous as well as lagged impacts of unionization, it is likely that the quality of care benefits of unionization are partially due to union presence itself in addition to changes in staffing, work environment or wages that typically occur with a lag.

In addition to wage and moral effects, nurse unions also bargain to a greater degree than most unions on staffing and work load. In particular, many nurse unions try to cap staffing ratios and set limits on hours worked per shift. Lower patient to nurse staffing ratios help nurses focus on and be more attentive to the patients under their care and reduce fatigue. Lower staffing ratios have consistently been shown to improve patient outcomes, including studies that have relied on quasi-random sources of variation in staffing ratios (Bell and Redelmeier 2001, Aiken et al. 2002, Evans and Kim 2006). Notably, beginning in 2004 California implemented AB394, which mandated minimum nurse staffing ratios state wide. ${ }^{6}$ While implementation and enforcement of AB394 occurred towards the end of our sample period, the law was widely anticipated and hospitals may have begun increasing nurse-patient ratios prior to enforcement to ensure compliance. This unique institutional feature may reduce the likelihood that union negotiated reductions in nurse staffing ratios are the primary mechanism underlying our findings.

A final potential mechanism is that hospitals may respond to unionization by moving towards more capital intensive techniques of production and this, in turn, may improve patient outcomes. We note that the evidence by Sojourner et al. (2012) from nursing homes suggests that staffing actually declined (relative to case load) following unionization, at least in the case of union victories.

\footnotetext{
${ }^{6}$ See Cook et al. (2012) for a detailed description and an analysis of the law's impact on patient outcomes.
} 
The reduction in staffing in nursing homes by Sojourner et al. appears to be more consistent with increased capital intensity of production. However, as noted, the acute care hospitals we study are much more capital intensive than nursing homes to begin with and have quite different patterns of staffing, limiting our ability to extrapolate across the two studies.

\section{Conclusion}

In this paper, we examine the consequences of nurse unionization on health care quality. We find that hospitals with a succesful unionization experience a decline in incidence of hospitalacquired illnesses in comparison with hospitals which experience a failed unionization attempt, and in comparison with hospitals more broadly conditional upon linear time trends. This holds true across a broad range of nurse sensitive medical outcomes ranging from less serious illnesses such as urinary tract infections to critical ones such as in-hospital death. Our largest effects are for central nervous system complications such as delirium and depression as well as for metabolic derangement. These estimates show a decline of up to 58 percent for nervous system disorders such as delirium and depression and 17 percent for metabolic derangement. The in-hospital death estimates, in particular, incorporate the effect of strikes and other disruptions on mortality (Gruber, 2010) though they are small and statistically insignificant in our preferred specifications.

We find that our estimates likely represent a causal effect of unionization on quality of care as opposed to a shift towards reporting illnesses upon admissions after unionization, greater selectivity over sicker patients, or unionization occurring during hospital decline followed by mean regression. However, we do not currently have the data to separate out whether the effect of unionization is primarily through unionization itself, a change in pay, a change in staffing or a change in work rules. Future research could disentangled these mechanisms, using data on union contracts, pay and staffing information matched to hospitals, as well as data on patient transfers across hospitals. Moreover, with larger samples, regression discontinuity techniques could be used to gain better identification. All of these would be substantial value added for understanding medical labor markets and hospital care quality more generally. It would also be informative for better understanding behavioral responses to labor market changes. Lastly, they would be informative for formulating labor market policy in the health care industry. 


\section{References}

[1] Aiken, Linda H., Sean P. Clarke, Douglas M. Sloane, Julie Sochalski, and Jeffrey H. Silber (2002). "Hospital nurse staffing and patient mortality, nurse burnout, and job dissatisfaction." Journal of the American Medical Association 288(16): pp. 1987-1993.

[2] Ash, Michael and Jean Ann Seago (2004), "The Effect of Registered Nurses' Unions on Heart Attack Mortality?", Industrial and Labor Relations Review 57(3), pp. 422-442.

[3] Bell, Chaim M., and Donald A. Redelmeier (2001) "Mortality among patients admitted to hospitals on weekends as compared with weekdays." New England Journal of Medicine 345(9): pp. 663-668.

[4] Card, David (1996), "The Effect of Unions on the Structure of Wages: A Longitudinal Analysis", Econometrica, 64(4): pp. 957-979.

[5] Cook, Andrew, Gaynor, Martin, Stephens, Melvin and Taylor, Lowell (2012), "The effect of a nurse staffing mandate on patient health outcome: Evidence from California's minimum staffing regulation", Journal of Health Economics 31(1), pp. 340-348.

[6] Dinardo, John and David S. Lee (2004), "Economic Impacts of New Unionization on Private Sector Employers: 1984-2001", Quarterly Journal of Economics 119(4): pp. 1383-1441.

[7] Evans, William N., and Beomsoo Kim (2006), "Patient outcomes when hospitals experience a surge in admissions." Journal of Health Economics 25(2): pp. 365-388.

[8] Frandsen, Brigham (2010), "Union wage setting and the distribution of employee earnings: Evidence from certification elections", working paper.

[9] Freeman, Richard and James Medoff (1984), What Do Unions Do?, Basic Books.

[10] Gruber, Jonathan and Samuel Kleiner (2010), "Do Strikes Kill?", American Economic Journal: Economic Policy 4(1), pp. 127-157.

[11] Hirsch, Barry T., and Edward J. Schumacher (1998), "Union wages, rents, and skills in health care labor markets." Journal of Labor Research 19(1): pp. 125-147.

[12] Hirsch, Barry T. (2004). "What Do Unions Do for Economic Performance?", Journal of Labor Research 25(3): pp. 415-455. 
[13] Krueger, Alan and Alexandre Mas (2004), "Strikes, Scabs and Tread Separations: Labor Strife and the Production of Defective Bridgestone/Firestone Tires", Journal of Political Economy 112(2), pp. 253-289.

[14] Lee, Lung-Fei (1978), "Unionism and Wage Rates: A Simultaneous Equations Model with Qualitative and Limited Dependent Variables,", International Economic Review: 19, pp. 415433.

[15] Lee, David, and Alexandre Mas (2012), "Long-Run Impacts of Unions on Firms: New Evidence from Financial Markets, 1961-1999", Quarterly Journal of Economics 127(1): pp. 333-378.

[16] Lewis, H. Gregg (1963), Unionism and Relative Wages in the United States: an Empirical Inquiry, University of Chicago Press: Chicago, Ill.

[17] Mas, Alexandre (2006), "Pay, Reference Points, Police Performance", Quarterly Journal of Economics 121(3), pp. 783-821.

[18] Mas, Alexandre (2008), "Labor Unrest and the Quality of Production: Evidence from the Construction Equipment Resale Market", Review of Economic Studies 75, pp. 229-258.

[19] Matsudaira, Jordan (forthcoming), "Monopsony in the Low-Wage Labor Market? Evidence from Minimum Nurse Staffing Regulations", Review of Economics and Statistics.

[20] McCrary, Justin (2007), "The Effect of Court-Ordered Hiring Quotas on the Composition and Quality of Police", American Economic Review 97(1), pp. 318-353.

[21] Needleman, Jack, Peter Buerhaus, Soren Mattke, Maureen Stewart, and Katya Zelevinsky (2002), "Nurse Staffing Levels and the Quality of Care in Hospitals", New England Journal of Medicine 346(22), pp. 1715-1722.

[22] Needleman, J., Buerhaus, P., Pankratz, S., Leibson, C., Stevens, S., and Harris, M. (2011), "Nurse staffing and inpatient hospital mortality", New England Journal of Medicine 364, pp.1037-1045.

[23] Propper, Carol and John Van Reenen (2010). "Can pay regulation kill? Panel data evidence on the effect of labor market outcomes on hospital performance", Journal of Political Economy 118(2), pp. 222-273. 
[24] Seago, Jean Ann, Joanne Spetz, Michael Ash, Carolina-Nicole Herrera, and Dennis Keane (2011). "Hospital RN job satisfaction and nurse unions." Journal of Nursing Administration 41(3): pp. 109-114.

[25] Schumacher, Edward J (1997), "Relative wages and exit behavior among registered nurses." Journal of Labor Research 18(4): pp. 581-592.

[26] Sojourner, Aaron, Robert Town, David C. Grabowski, and Michelle Chen (2012), "Impacts of Unionization on Employment, Product Quality and Productivity: Regression Discontinuity Evidence From Nursing Homes", NBER Working Paper.

[27] Spetz, Joanne, Michael Ash, Charalampos Konstantinidis, and Carolina Herrera (2011), "The effect of unions on the distribution of wages of hospital employed registered nurses in the United States." Journal of Clinical Nursing 20(1-2): pp. 60-67.

[28] Wessels, Walter (1994), "Do Unionized Firms Hire Better Workers?" Economic Inquiry 32(4): pp. 616-29. 
Table 1: Means and Standard Deviations by Union Event Status

\begin{tabular}{|c|c|c|c|c|}
\hline & Full Sample & No Election & Win Election & Lose Election \\
\hline Female & $\begin{array}{c}0.592 \\
(0.0581)\end{array}$ & $\begin{array}{c}0.590 \\
(0.0602)\end{array}$ & $\begin{array}{c}0.600 \\
(0.0464)\end{array}$ & $\begin{array}{c}0.599 \\
(0.0203)\end{array}$ \\
\hline White & $\begin{array}{c}0.492 \\
(0.269)\end{array}$ & $\begin{array}{c}0.483 \\
(0.269)\end{array}$ & $\begin{array}{c}0.538 \\
(0.272)\end{array}$ & $\begin{array}{c}0.587 \\
(0.245)\end{array}$ \\
\hline Black & $\begin{array}{c}0.0752 \\
(0.0943)\end{array}$ & $\begin{array}{c}0.0802 \\
(0.0995)\end{array}$ & $\begin{array}{c}0.0482 \\
(0.0470)\end{array}$ & $\begin{array}{c}0.0391 \\
(0.0434)\end{array}$ \\
\hline Latino & $\begin{array}{c}0.270 \\
(0.196)\end{array}$ & $\begin{array}{c}0.274 \\
(0.203)\end{array}$ & $\begin{array}{c}0.249 \\
(0.157)\end{array}$ & $\begin{array}{c}0.218 \\
(0.0959)\end{array}$ \\
\hline Asian & $\begin{array}{c}0.0633 \\
(0.0776)\end{array}$ & $\begin{array}{c}0.0633 \\
(0.0742)\end{array}$ & $\begin{array}{l}0.0680 \\
(0.102)\end{array}$ & $\begin{array}{c}0.0388 \\
(0.0385)\end{array}$ \\
\hline Under 18 & $\begin{array}{c}0.220 \\
(0.138)\end{array}$ & $\begin{array}{c}0.219 \\
(0.133)\end{array}$ & $\begin{array}{c}0.232 \\
(0.174)\end{array}$ & $\begin{array}{c}0.179 \\
(0.0569)\end{array}$ \\
\hline Over 65 & $\begin{array}{c}0.391 \\
(0.155)\end{array}$ & $\begin{array}{c}0.386 \\
(0.158)\end{array}$ & $\begin{array}{c}0.411 \\
(0.147)\end{array}$ & $\begin{array}{c}0.460 \\
(0.0794)\end{array}$ \\
\hline Urinary Tract Infection & $\begin{array}{c}5.936 \\
(7.101)\end{array}$ & $\begin{array}{c}5.684 \\
(7.336)\end{array}$ & $\begin{array}{c}7.719 \\
(5.671)\end{array}$ & $\begin{array}{c}5.760 \\
(2.920)\end{array}$ \\
\hline Pressure Ulcer & $\begin{array}{c}0.871 \\
(1.584)\end{array}$ & $\begin{array}{c}0.863 \\
(1.675)\end{array}$ & $\begin{array}{c}0.959 \\
(0.947)\end{array}$ & $\begin{array}{c}0.744 \\
(0.665)\end{array}$ \\
\hline Hospital Aquired Pneumonia & $\begin{array}{c}8.489 \\
(5.950)\end{array}$ & $\begin{array}{c}8.242 \\
(6.061)\end{array}$ & $\begin{array}{c}10.16 \\
(5.222)\end{array}$ & $\begin{array}{c}8.693 \\
(3.861)\end{array}$ \\
\hline Hospital Aquired Sepsis & $\begin{array}{c}0.527 \\
(1.044)\end{array}$ & $\begin{array}{c}0.508 \\
(1.065)\end{array}$ & $\begin{array}{c}0.690 \\
(0.977)\end{array}$ & $\begin{array}{c}0.375 \\
(0.372)\end{array}$ \\
\hline Shock or Cardiac Arrest & $\begin{array}{c}3.270 \\
(2.823)\end{array}$ & $\begin{array}{c}3.224 \\
(2.957)\end{array}$ & $\begin{array}{c}3.588 \\
(1.848)\end{array}$ & $\begin{array}{c}3.261 \\
(1.901)\end{array}$ \\
\hline Upper Gastrointestinal Bleeding & $\begin{array}{c}1.003 \\
(1.529)\end{array}$ & $\begin{array}{c}0.960 \\
(1.600)\end{array}$ & $\begin{array}{c}1.302 \\
(1.051)\end{array}$ & $\begin{array}{c}0.995 \\
(0.636)\end{array}$ \\
\hline Pulmonary Failure & $\begin{array}{c}3.410 \\
(3.082)\end{array}$ & $\begin{array}{c}3.241 \\
(3.008)\end{array}$ & $\begin{array}{c}4.540 \\
(3.387)\end{array}$ & $\begin{array}{c}3.589 \\
(2.854)\end{array}$ \\
\hline Metabolic Derangement & $\begin{array}{c}0.650 \\
(0.639)\end{array}$ & $\begin{array}{c}0.632 \\
(0.645)\end{array}$ & $\begin{array}{c}0.728 \\
(0.528)\end{array}$ & $\begin{array}{c}0.869 \\
(0.822)\end{array}$ \\
\hline Deep Venous Thrombosis & $\begin{array}{c}1.158 \\
(1.259)\end{array}$ & $\begin{array}{c}1.108 \\
(1.252)\end{array}$ & $\begin{array}{c}1.492 \\
(1.350)\end{array}$ & $\begin{array}{c}1.222 \\
(0.666)\end{array}$ \\
\hline Central Nervous Complication & $\begin{array}{c}1.041 \\
(1.698)\end{array}$ & $\begin{array}{c}0.988 \\
(1.696)\end{array}$ & $\begin{array}{c}1.379 \\
(1.755)\end{array}$ & $\begin{array}{c}1.184 \\
(1.262)\end{array}$ \\
\hline Wound Infection & $\begin{array}{c}1.521 \\
(1.288)\end{array}$ & $\begin{array}{c}1.483 \\
(1.277)\end{array}$ & $\begin{array}{c}1.761 \\
(1.399)\end{array}$ & $\begin{array}{c}1.619 \\
(0.906)\end{array}$ \\
\hline Failure to Rescue & $\begin{array}{c}6.766 \\
(4.583)\end{array}$ & $\begin{array}{c}6.727 \\
(4.870)\end{array}$ & $\begin{array}{c}6.974 \\
(2.342)\end{array}$ & $\begin{array}{c}7.077 \\
(2.232)\end{array}$ \\
\hline In Hospital Death & $\begin{array}{c}22.51 \\
(18.50)\end{array}$ & $\begin{array}{c}22.42 \\
(19.85)\end{array}$ & $\begin{array}{c}23.02 \\
(6.948)\end{array}$ & $\begin{array}{c}23.01 \\
(4.975)\end{array}$ \\
\hline Number of Hospitals & 666 & 616 & 39 & 11 \\
\hline Hospital Years & 4987 & 4522 & 385 & 80 \\
\hline
\end{tabular}

Notes. Standard deviations are in parenthesis. Patient outcomes are measured as incidence per thousand patients. Statistics are weighted by total number of patients. 
Table 2: Impact of Unionization on Nurse-Sensitive Patient Outcomes

\begin{tabular}{|c|c|c|c|c|}
\hline \multirow[b]{2}{*}{ UTI } & \multicolumn{2}{|c|}{ Full Sample } & \multicolumn{2}{|c|}{ Election Sample } \\
\hline & $\begin{array}{c}0.339 \\
(0.722)\end{array}$ & $\begin{array}{c}-0.712 \\
(0.766)\end{array}$ & $\begin{array}{c}-1.124^{*} \\
(0.636)\end{array}$ & $\begin{array}{c}-0.865 \\
(0.719)\end{array}$ \\
\hline PRU & $\begin{array}{c}0.079 \\
(0.140)\end{array}$ & $\begin{array}{c}-0.134 \\
(0.201)\end{array}$ & $\begin{array}{l}-0.185 \\
(0.164)\end{array}$ & $\begin{array}{c}-0.274 \\
(0.210)\end{array}$ \\
\hline HAP & $\begin{array}{c}0.393 \\
(0.698)\end{array}$ & $\begin{array}{l}-0.077 \\
(0.704)\end{array}$ & $\begin{array}{c}-1.556^{* *} \\
(0.715)\end{array}$ & $\begin{array}{l}-0.459 \\
(0.636)\end{array}$ \\
\hline HAS & $\begin{array}{c}0.050 \\
(0.051)\end{array}$ & $\begin{array}{c}-0.012 \\
(0.076)\end{array}$ & $\begin{array}{c}-0.011 \\
(0.091)\end{array}$ & $\begin{array}{l}-0.040 \\
(0.127)\end{array}$ \\
\hline SCA & $\begin{array}{c}-0.063 \\
(0.267)\end{array}$ & $\begin{array}{l}-0.418 \\
(0.390)\end{array}$ & $\begin{array}{c}-0.326 \\
(0.304)\end{array}$ & $\begin{array}{c}-0.301 \\
(0.434)\end{array}$ \\
\hline UGB & $\begin{array}{c}0.022 \\
(0.195)\end{array}$ & $\begin{array}{c}0.011 \\
(0.266)\end{array}$ & $\begin{array}{c}-0.112 \\
(0.263)\end{array}$ & $\begin{array}{c}0.008 \\
(0.378)\end{array}$ \\
\hline PNF & $\begin{array}{c}0.058 \\
(0.439)\end{array}$ & $\begin{array}{l}-0.736 \\
(0.543)\end{array}$ & $\begin{array}{c}-1.140^{* *} \\
(0.488)\end{array}$ & $\begin{array}{l}-0.771 \\
(0.584)\end{array}$ \\
\hline MDB & $\begin{array}{c}0.012 \\
(0.037)\end{array}$ & $\begin{array}{c}-0.154^{*} \\
(0.081)\end{array}$ & $\begin{array}{c}-0.115^{*} \\
(0.061)\end{array}$ & $\begin{array}{c}-0.127^{* *} \\
(0.058)\end{array}$ \\
\hline DVT & $\begin{array}{c}-0.011 \\
(0.099)\end{array}$ & $\begin{array}{c}-0.180 \\
(0.202)\end{array}$ & $\begin{array}{c}-0.208 \\
(0.155)\end{array}$ & $\begin{array}{c}-0.101 \\
(0.176)\end{array}$ \\
\hline $\mathrm{CNS}$ & $\begin{array}{c}-0.064 \\
(0.214)\end{array}$ & $\begin{array}{c}-0.604^{* *} \\
(0.300)\end{array}$ & $\begin{array}{c}-0.707^{* *} \\
(0.275)\end{array}$ & $\begin{array}{c}-0.796^{* * *} \\
(0.243)\end{array}$ \\
\hline WIN & $\begin{array}{l}-0.086 \\
(0.078)\end{array}$ & $\begin{array}{c}-0.204 \\
(0.126)\end{array}$ & $\begin{array}{c}-0.272^{* *} \\
(0.104)\end{array}$ & $\begin{array}{l}-0.149 \\
(0.113)\end{array}$ \\
\hline FTR & $\begin{array}{c}-0.573^{* * *} \\
(0.213)\end{array}$ & $\begin{array}{c}-0.241 \\
(0.298)\end{array}$ & $\begin{array}{c}-0.385 \\
(0.354)\end{array}$ & $\begin{array}{l}-0.324 \\
(0.376)\end{array}$ \\
\hline IHD & $\begin{array}{c}-1.196^{* * *} \\
(0.410)\end{array}$ & $\begin{array}{c}-0.394 \\
(0.530)\end{array}$ & $\begin{array}{c}-1.256^{* *} \\
(0.583)\end{array}$ & $\begin{array}{c}-0.504 \\
(0.637)\end{array}$ \\
\hline ALL & $\begin{array}{c}0.004 \\
(0.025)\end{array}$ & $\begin{array}{c}-0.056^{* *} \\
(0.025)\end{array}$ & $\begin{array}{c}-0.091^{* * *} \\
(0.024)\end{array}$ & $\begin{array}{c}-0.061^{* *} \\
(0.025)\end{array}$ \\
\hline $\mathrm{N}$ & 4987 & 4987 & 465 & 465 \\
\hline Hospital Trends & $\mathrm{N}$ & $\mathrm{Y}$ & $\mathrm{N}$ & $\mathrm{Y}$ \\
\hline
\end{tabular}

Notes. Dependent variables are measured as the incidence rate per thousand patients for the specified condition, except for the combined measure, ALL, which is measured in standard deviation units. Full Sample results are estimated using all hospitals, while Election Sample results are estimated using only hospitals that had either a winning or a losing unionization attempt. All specifications contain hospital and year fixed effects, and specifications 2 and 4 contain hospital specific time trends. All specifications additionally control for the proportion of patients who are female, white, black, hispanic, and asian, 8 age categories, 25 major diagnostic categories, the proportion of patients who suffered from the specified condition when admitted to the hospital (where applicable), as well as interactions between major diagnostic categories, age and gender. All models are weighted by the total number of patients. Robust standard errors, cDisstered by hospital, are in parentheses.

${ }^{*} p<0.10, * * p<0.5$, *** $p<0.01$ 
Table 3: Dynamic Effects of Unionization on Mean Standardized Outcome

\begin{tabular}{|c|c|c|c|c|}
\hline \multirow[b]{2}{*}{2 yrs pre-election } & \multicolumn{2}{|c|}{ Full Sample } & \multicolumn{2}{|c|}{ Election Sample } \\
\hline & $\begin{array}{c}0.057^{* *} \\
(0.023)\end{array}$ & $\begin{array}{c}-0.004 \\
(0.024)\end{array}$ & $\begin{array}{c}0.004 \\
(0.032)\end{array}$ & $\begin{array}{c}0.003 \\
(0.031)\end{array}$ \\
\hline 1 yr pre-election & $\begin{array}{c}0.012 \\
(0.015)\end{array}$ & $\begin{array}{l}-0.008 \\
(0.018)\end{array}$ & $\begin{array}{c}-0.020 \\
(0.018)\end{array}$ & $\begin{array}{l}-0.005 \\
(0.026)\end{array}$ \\
\hline year of election & $\begin{array}{l}-0.027 \\
(0.023)\end{array}$ & $\begin{array}{l}-0.057^{* *} \\
(0.026)\end{array}$ & $\begin{array}{l}-0.071^{\text {*** }} \\
(0.024)\end{array}$ & $\begin{array}{l}-0.062^{* *} \\
(0.029)\end{array}$ \\
\hline 1 yr post-election & $\begin{array}{l}-0.007 \\
(0.016)\end{array}$ & $\begin{array}{l}-0.038^{* *} \\
(0.016)\end{array}$ & $\begin{array}{l}-0.051^{* *} \\
(0.024)\end{array}$ & $\begin{array}{c}-0.023 \\
(0.027)\end{array}$ \\
\hline 2 yrs post-election & $\begin{array}{c}0.005 \\
(0.023)\end{array}$ & $\begin{array}{l}-0.024 \\
(0.029)\end{array}$ & $\begin{array}{c}0.019 \\
(0.026)\end{array}$ & $\begin{array}{c}0.012 \\
(0.033)\end{array}$ \\
\hline 3 yrs post-election & $\begin{array}{l}-0.011 \\
(0.013)\end{array}$ & $\begin{array}{c}-0.034 \\
(0.022)\end{array}$ & $\begin{array}{c}-0.006 \\
(0.022)\end{array}$ & $\begin{array}{l}-0.014 \\
(0.028)\end{array}$ \\
\hline$\geq 4$ yrs post-election & $\begin{array}{l}-0.000 \\
(0.041)\end{array}$ & $\begin{array}{l}-0.015 \\
(0.038)\end{array}$ & $\begin{array}{l}-0.055 \\
(0.041)\end{array}$ & $\begin{array}{l}-0.011 \\
(0.042)\end{array}$ \\
\hline Short term effect: $1 \mathrm{yr}$ & $\begin{array}{l}-.033 \\
(.024)\end{array}$ & $\begin{array}{l}-.094^{* * *} \\
(.025)\end{array}$ & $\begin{array}{l}-.121^{* * *} \\
(.032)\end{array}$ & $\begin{array}{l}-.085^{* *} \\
(.039)\end{array}$ \\
\hline Long term effect: $\geq 4$ yrs & $\begin{array}{l}-.039 \\
(.05)\end{array}$ & $\begin{array}{l}-.167^{* *} \\
(.071)\end{array}$ & $\begin{array}{l}-.162^{* *} \\
(.067)\end{array}$ & $\begin{array}{l}-.097 \\
(.091)\end{array}$ \\
\hline $\mathrm{N}$ & 4564 & 4564 & 452 & 452 \\
\hline Hospital Trends & $\mathrm{N}$ & $\mathrm{Y}$ & $\mathrm{N}$ & $\mathrm{Y}$ \\
\hline
\end{tabular}

Notes. Dependent variable is the mean standardized incidence rate across all conditions. Independent variables are leads and lags of union status, as indicated. The reported short-term effect is the sum of the contempraneous union status variable and the one year lag, while the reported long term effect is the sum of the contemporaneous union variable and the full set of lags. Full Sample results are estimated using all hospitals, while Election Sample results are estimated using only hospitals that had either a winning or a losing unionization attempt. All specifications contain hospital and year fixed effects, and specifications 2 and 4 contain hospital specific time trends. All specifications additionally control for the proportion of patients who are female, white, black, hispanic, and asian, 8 age categories, 25 major diagnostic categories, the proportion of patients who suffered from the specified condition when admitted to the hospital (where applicable), as well as interactions between major diagnostic categories, age and gender. All models are weighted by the total number of patients. Robust standard errors, clustered by hospital, are in parentheses.

${ }^{*} p<0.10, * * p<0.5$, *** $p<0.01$ 
Table 4: Impact of Unionization on Patient Demographics

\begin{tabular}{lccccc}
\hline & \multicolumn{2}{c}{ Full Sample } & & \multicolumn{2}{c}{ Election Sample } \\
\cline { 2 - 3 } \cline { 6 - 6 } Log Patient Total & -0.021 & -0.019 & & -0.023 & -0.017 \\
& $(0.030)$ & $(0.028)$ & & $(0.035)$ & $(0.028)$ \\
Female & 0.002 & 0.005 & & -0.003 & 0.003 \\
& $(0.004)$ & $(0.007)$ & & $(0.005)$ & $(0.007)$ \\
Non-White & -0.008 & 0.009 & & 0.002 & 0.004 \\
& $(0.015)$ & $(0.015)$ & & $(0.017)$ & $(0.017)$ \\
Under 18 & -0.015 & -0.007 & & -0.022 & -0.007 \\
& $(0.019)$ & $(0.007)$ & & $(0.017)$ & $(0.007)$ \\
Over 65 & 0.004 & -0.001 & & 0.019 & 0.001 \\
& $(0.015)$ & $(0.008)$ & & $(0.014)$ & $(0.008)$ \\
N & 4987 & 4987 & & 465 & 465 \\
Hospital Trends & $\mathrm{N}$ & $\mathrm{Y}$ & $\mathrm{N}$ & $\mathrm{Y}$ \\
\hline
\end{tabular}

Notes. Dependent variables are patient demographics as indicated. Female, Non-White, Under 18 and Over 65 are measured as proportions. Full Sample results are estimated using all hospitals, while Election Sample results are estimated using only hospitals that had either a winning or a losing unionization attempt. All specifications contain hospital and year fixed effects, and specifications 2 and 4 contain hospital specific time trends. All models are weighted by the total number of patients. Robust standard errors, clustered by

hospital, are in parentheses.
${ }^{*} p<0.10, * * p<0.5,{ }^{* *} p<0.01$ 
Table 5: Restricted Time Windows Around Unionizations

\begin{tabular}{|c|c|c|c|c|c|c|}
\hline & \multicolumn{3}{|c|}{ Full Sample } & \multicolumn{3}{|c|}{ Election Sample } \\
\hline \multicolumn{7}{|c|}{ Panel A: Restricted Pre-Election Period } \\
\hline & 2 years & 4 years & 6 years & 2 years & 4 years & 6 years \\
\hline \multirow{3}{*}{ ALL } & pre election & pre election & pre election & pre election & pre election & pre election \\
\hline & -0.032 & $-0.050^{*}$ & $-0.059 * *$ & $-0.063^{* *}$ & $-0.049^{*}$ & $-0.056^{* *}$ \\
\hline & $(0.031)$ & $(0.029)$ & $(0.027)$ & $(0.025)$ & $(0.027)$ & $(0.025)$ \\
\hline $\mathrm{N}$ & 4867 & 4918 & 4953 & 345 & 396 & 431 \\
\hline \multicolumn{7}{|c|}{ Panel B: Restricted Post-Election Period } \\
\hline & 2 years & 4 years & 6 years & 2 years & 4 years & 6 years \\
\hline \multirow{3}{*}{ ALL } & post election & post election & post election & post election & post election & post election \\
\hline & $-0.048^{*}$ & -0.035 & $-0.051^{* *}$ & -0.049 & -0.053 & $-0.065^{* *}$ \\
\hline & $(0.027)$ & $(0.026)$ & $(0.025)$ & $(0.041)$ & $(0.034)$ & $(0.028)$ \\
\hline $\mathrm{N}$ & 4864 & 4908 & 4942 & 342 & 386 & 420 \\
\hline
\end{tabular}

Notes. Dependent variable is the mean standardized incidence rate across all conditions. In Panel A, the sample of unionizing hospitals is restricted to the specified number of years before the winning election took place, while in Panel $\mathrm{B}$ it is restricted to the specified number of years after the election took place. Full Sample results are estimated using all hospitals, while Election Sample results are estimated using only hospitals that had either a winning or a losing unionization attempt. All specifications contain hospital fixed effects, year fixed effects, and hospital specific time trends. All specifications additionally control for the proportion of patients who are female, white, black, hispanic, and asian, 8 age categories, 25 major diagnostic categories, the proportion of patients who suffered from the specified condition when admitted to the hospital (where applicable), as well as interactions between major diagnostic categories, age and gender. All models are weighted by the total number of patients. Robust standard errors, clustered by hospital, are in parentheses. $* p<0.10$, ** $p<0.5$, *** $p<0.01$ 
Table 6: Robustness Checks

\begin{tabular}{|c|c|c|c|c|c|c|c|c|}
\hline & \multicolumn{4}{|c|}{ Full Sample } & \multicolumn{4}{|c|}{ Election Sample } \\
\hline UTI & $\begin{array}{c}\text { with post } \\
\text { dummy } \\
-0.752 \\
(0.963)\end{array}$ & $\begin{array}{c}\text { quadratic } \\
\text { trends } \\
-0.713 \\
(0.766)\end{array}$ & $\begin{array}{c}\text { trends by } \\
\text { pre and post } \\
-0.554 \\
(0.928)\end{array}$ & $\begin{array}{c}\text { No POA } \\
\text { Controls } \\
-1.471^{*} \\
(0.852)\end{array}$ & $\begin{array}{c}\text { with post } \\
\text { dummy } \\
-0.978 \\
(1.174)\end{array}$ & $\begin{array}{c}\text { quadratic } \\
\text { trends } \\
-0.866 \\
(0.719)\end{array}$ & $\begin{array}{c}\text { trends by } \\
\text { pre and post } \\
-1.246 \\
(1.300)\end{array}$ & $\begin{array}{c}\text { No POA } \\
\text { Controls } \\
-1.742^{* *} \\
(0.823)\end{array}$ \\
\hline PRU & $\begin{array}{l}-0.148 \\
(0.238)\end{array}$ & $\begin{array}{c}-0.134 \\
(0.201)\end{array}$ & $\begin{array}{l}-0.182 \\
(0.261)\end{array}$ & $\begin{array}{c}-0.222 \\
(0.210)\end{array}$ & $\begin{array}{c}0.013 \\
(0.291)\end{array}$ & $\begin{array}{c}-0.273 \\
(0.210)\end{array}$ & $\begin{array}{c}-0.006 \\
(0.286)\end{array}$ & $\begin{array}{c}-0.377^{*} \\
(0.219)\end{array}$ \\
\hline HAP & $\begin{array}{c}-2.034 \\
(1.463)\end{array}$ & $\begin{array}{l}-0.076 \\
(0.706)\end{array}$ & $\begin{array}{l}-1.745 \\
(1.532)\end{array}$ & $\begin{array}{c}0.158 \\
(0.819)\end{array}$ & $\begin{array}{c}-3.304^{* * *} \\
(1.039)\end{array}$ & $\begin{array}{l}-0.460 \\
(0.637)\end{array}$ & $\begin{array}{c}-3.105^{* * *} \\
(1.149)\end{array}$ & $\begin{array}{c}-0.590 \\
(0.974)\end{array}$ \\
\hline HAS & $\begin{array}{c}0.046 \\
(0.102)\end{array}$ & $\begin{array}{c}-0.012 \\
(0.076)\end{array}$ & $\begin{array}{c}0.034 \\
(0.109)\end{array}$ & $\begin{array}{l}-0.005 \\
(0.131)\end{array}$ & $\begin{array}{l}-0.049 \\
(0.168)\end{array}$ & $\begin{array}{l}-0.040 \\
(0.127)\end{array}$ & $\begin{array}{c}-0.046 \\
(0.169)\end{array}$ & $\begin{array}{l}-0.089 \\
(0.171)\end{array}$ \\
\hline SCA & $\begin{array}{c}-1.886^{* * *} \\
(0.727)\end{array}$ & $\begin{array}{l}-0.417 \\
(0.390)\end{array}$ & $\begin{array}{c}-1.673^{* *} \\
(0.739)\end{array}$ & $\begin{array}{l}-0.342 \\
(0.415)\end{array}$ & $\begin{array}{c}-1.610^{* *} \\
(0.647)\end{array}$ & $\begin{array}{l}-0.301 \\
(0.434)\end{array}$ & $\begin{array}{c}-1.454^{* *} \\
(0.649)\end{array}$ & $\begin{array}{l}-0.166 \\
(0.511)\end{array}$ \\
\hline UGB & $\begin{array}{c}-0.043 \\
(0.289)\end{array}$ & $\begin{array}{c}0.011 \\
(0.266)\end{array}$ & $\begin{array}{c}0.093 \\
(0.376)\end{array}$ & $\begin{array}{c}-0.073 \\
(0.267)\end{array}$ & $\begin{array}{c}0.152 \\
(0.389)\end{array}$ & $\begin{array}{c}0.008 \\
(0.378)\end{array}$ & $\begin{array}{c}0.223 \\
(0.437)\end{array}$ & $\begin{array}{l}-0.044 \\
(0.406)\end{array}$ \\
\hline $\mathrm{PNF}$ & $\begin{array}{l}-1.036 \\
(0.832)\end{array}$ & $\begin{array}{c}-0.736 \\
(0.544)\end{array}$ & $\begin{array}{c}-1.104 \\
(1.002)\end{array}$ & $\begin{array}{l}-0.781 \\
(0.678)\end{array}$ & $\begin{array}{c}-1.243^{*} \\
(0.731)\end{array}$ & $\begin{array}{c}-0.771 \\
(0.584)\end{array}$ & $\begin{array}{l}-1.464 \\
(0.906)\end{array}$ & $\begin{array}{c}-1.187 \\
(0.750)\end{array}$ \\
\hline MDB & $\begin{array}{c}-0.209 \\
(0.156)\end{array}$ & $\begin{array}{c}-0.154^{*} \\
(0.081)\end{array}$ & $\begin{array}{c}-0.175 \\
(0.169)\end{array}$ & $\begin{array}{c}-0.205^{* *} \\
(0.098)\end{array}$ & $\begin{array}{c}-0.087 \\
(0.164)\end{array}$ & $\begin{array}{c}-0.127^{* *} \\
(0.058)\end{array}$ & $\begin{array}{c}-0.037 \\
(0.189)\end{array}$ & $\begin{array}{c}-0.234^{* *} \\
(0.105)\end{array}$ \\
\hline DVT & $\begin{array}{c}-0.467^{*} \\
(0.261)\end{array}$ & $\begin{array}{l}-0.180 \\
(0.202)\end{array}$ & $\begin{array}{l}-0.301 \\
(0.198)\end{array}$ & $\begin{array}{l}-0.351 \\
(0.223)\end{array}$ & $\begin{array}{l}-0.342 \\
(0.257)\end{array}$ & $\begin{array}{l}-0.101 \\
(0.176)\end{array}$ & $\begin{array}{c}-0.302 \\
(0.286)\end{array}$ & $\begin{array}{c}-0.360^{*} \\
(0.188)\end{array}$ \\
\hline CNS & $\begin{array}{l}-0.620 \\
(0.536)\end{array}$ & $\begin{array}{c}-0.602^{* *} \\
(0.300)\end{array}$ & $\begin{array}{c}-0.196 \\
(0.429)\end{array}$ & $\begin{array}{c}-0.789 * * \\
(0.399)\end{array}$ & $\begin{array}{c}-0.895^{*} \\
(0.524)\end{array}$ & $\begin{array}{c}-0.795^{* * *} \\
(0.243)\end{array}$ & $\begin{array}{l}-0.757 \\
(0.542)\end{array}$ & $\begin{array}{c}-1.071^{* * *} \\
(0.359)\end{array}$ \\
\hline WIN & $\begin{array}{l}-0.085 \\
(0.213)\end{array}$ & $\begin{array}{l}-0.204 \\
(0.126)\end{array}$ & $\begin{array}{l}-0.040 \\
(0.202)\end{array}$ & $\begin{array}{l}-0.218 \\
(0.168)\end{array}$ & $\begin{array}{l}-0.001 \\
(0.205)\end{array}$ & $\begin{array}{l}-0.149 \\
(0.113)\end{array}$ & $\begin{array}{c}0.076 \\
(0.218)\end{array}$ & $\begin{array}{l}-0.219 \\
(0.175)\end{array}$ \\
\hline FTR & $\begin{array}{l}-0.587 \\
(0.567)\end{array}$ & $\begin{array}{c}-0.240 \\
(0.298)\end{array}$ & $\begin{array}{c}-0.487 \\
(0.569)\end{array}$ & $\begin{array}{l}-0.241 \\
(0.298)\end{array}$ & $\begin{array}{l}-0.463 \\
(0.723)\end{array}$ & $\begin{array}{l}-0.324 \\
(0.376)\end{array}$ & $\begin{array}{l}-0.438 \\
(0.722)\end{array}$ & $\begin{array}{l}-0.324 \\
(0.376)\end{array}$ \\
\hline IHD & $\begin{array}{c}-0.481 \\
(1.356)\end{array}$ & $\begin{array}{l}-0.395 \\
(0.530)\end{array}$ & $\begin{array}{l}-0.440 \\
(1.357)\end{array}$ & $\begin{array}{l}-0.394 \\
(0.530)\end{array}$ & $\begin{array}{c}-0.714 \\
(1.363)\end{array}$ & $\begin{array}{l}-0.505 \\
(0.637)\end{array}$ & $\begin{array}{l}-0.588 \\
(1.443)\end{array}$ & $\begin{array}{l}-0.504 \\
(0.637)\end{array}$ \\
\hline ALL & $\begin{array}{c}-0.091^{* *} \\
(0.045)\end{array}$ & $\begin{array}{c}-0.055^{* *} \\
(0.025)\end{array}$ & $\begin{array}{l}-0.069 \\
(0.044)\end{array}$ & $\begin{array}{c}-0.084^{* * *} \\
(0.031)\end{array}$ & $\begin{array}{c}-0.083^{* *} \\
(0.037)\end{array}$ & $\begin{array}{c}-0.061^{* *} \\
(0.025)\end{array}$ & $\begin{array}{c}-0.075^{*} \\
(0.043)\end{array}$ & $\begin{array}{c}-0.108 * * * \\
(0.036)\end{array}$ \\
\hline $\mathrm{N}$ & 4987 & 4987 & 4987 & 4987 & 465 & 465 & 465 & 465 \\
\hline
\end{tabular}

Notes. Dependent variables are measured as the incidence rate per thousand patients for the specified condition, except for the combined measure, ALL, which is measured in standard deviation units. All specifications contain hospital and year fixed effects as well as hospital specific time trends. Specifications 1 and 5 additionally contain a dummy indicating the period after an election has taken place; Specifications 2 and 6 additionally contain a quadratic hospital specific time trend; and specifications 3 and 7 additionally contain time trends specific to the pre-election and post-election periods. Full Sample results are estimated using all hospitals, while Election Sample results are estimated using only hospitals that had either a winning or a losing unionization attempt. All specifications additionally control for the proportion of patients who are female, white, black, hispanic, and asian, 8 age categories, and 25 major diagnostic categories, as well as interactions between major diagnostic categories, age and gender. All models except for 4 and 8 additionally control for the proportion of patients who suffered from the specified condition when admitted to the hospital. All models are weighted by the total number of patients. Robust standard errors, clustered by hospital, are in parentheses. $* p<0.10, * * p<0.5, * * * p<0.01$ 
Figure 1: Percentage Changes in Incidence of Nurse Sensitive Outcomes from Unionization
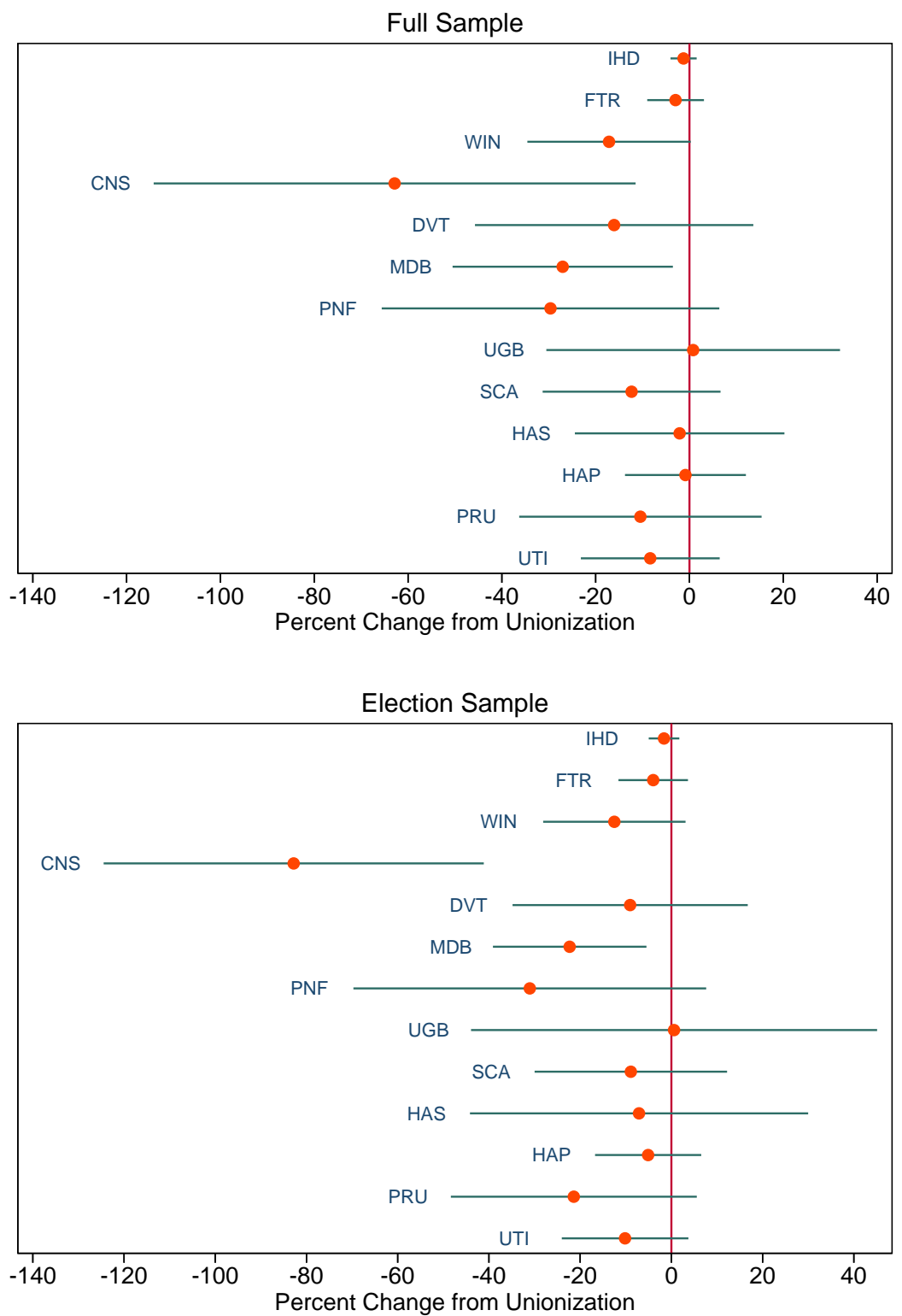

Notes: Figures show point estimates of unionization effects from Table 2 converted to percentages using full sample means of each outcomes, while bars display corresponding $90 \%$ confidence intervals. All specifications contain hospital and year fixed effects, hospital specific time trends, and demographic controls and are weighted by the total number of patients. 
Figure 2: Dynamic Response of Mean Standardized Outcome from Unionization

\section{Full Sample}
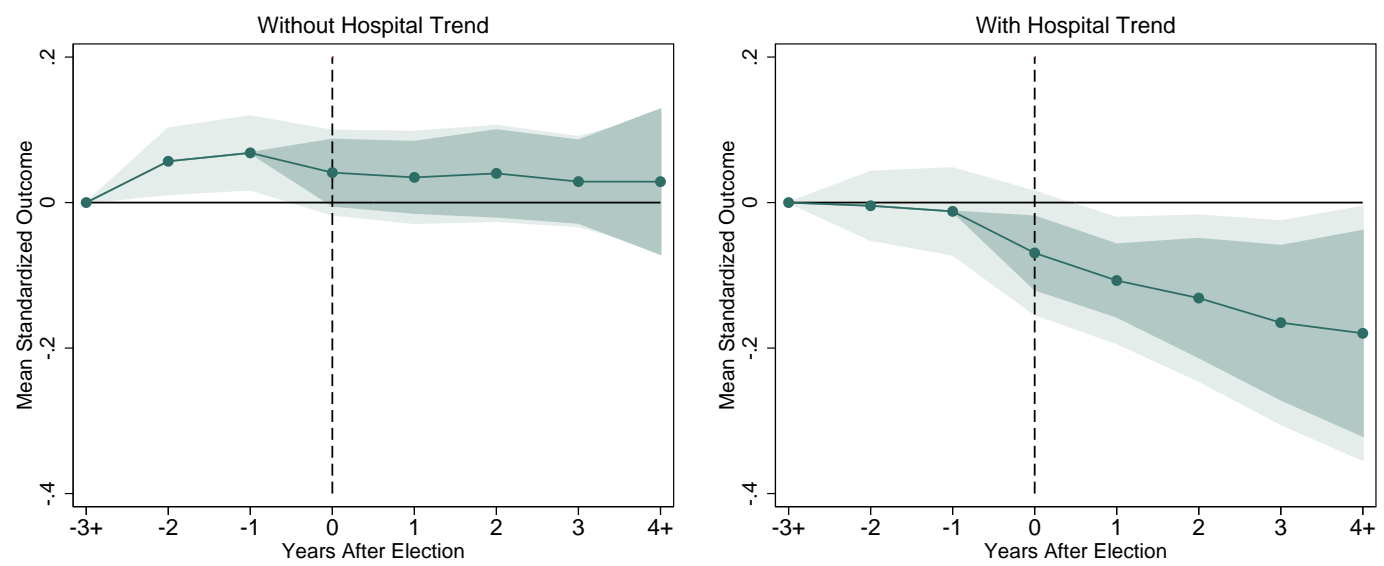

\section{Election Sample}
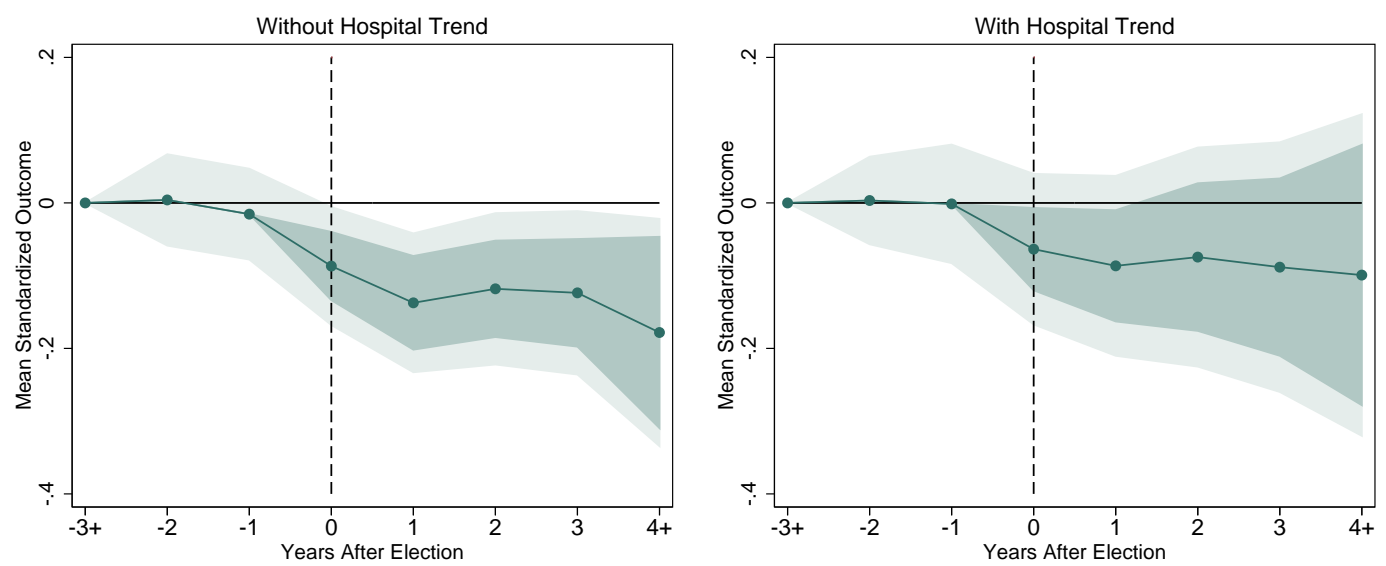

Notes: Dependent variable is the mean standardized incidence rate across all conditions. Figures show the cumulative sum of coefficients beginning with the 2 year lead. All specifications contain hospital and year fixed effects and demographic controls, as well as hospital specific time trends as
indicated, and are weighted by the total number of patients. Lighter shaded confidence interval is for year t relative to a baseline of 3 years before unionization, while the darker shaded confidence interval is for year t relative to a baseline immediately prior to the election. 
Figure A1: Distribution of Union Elections By Year

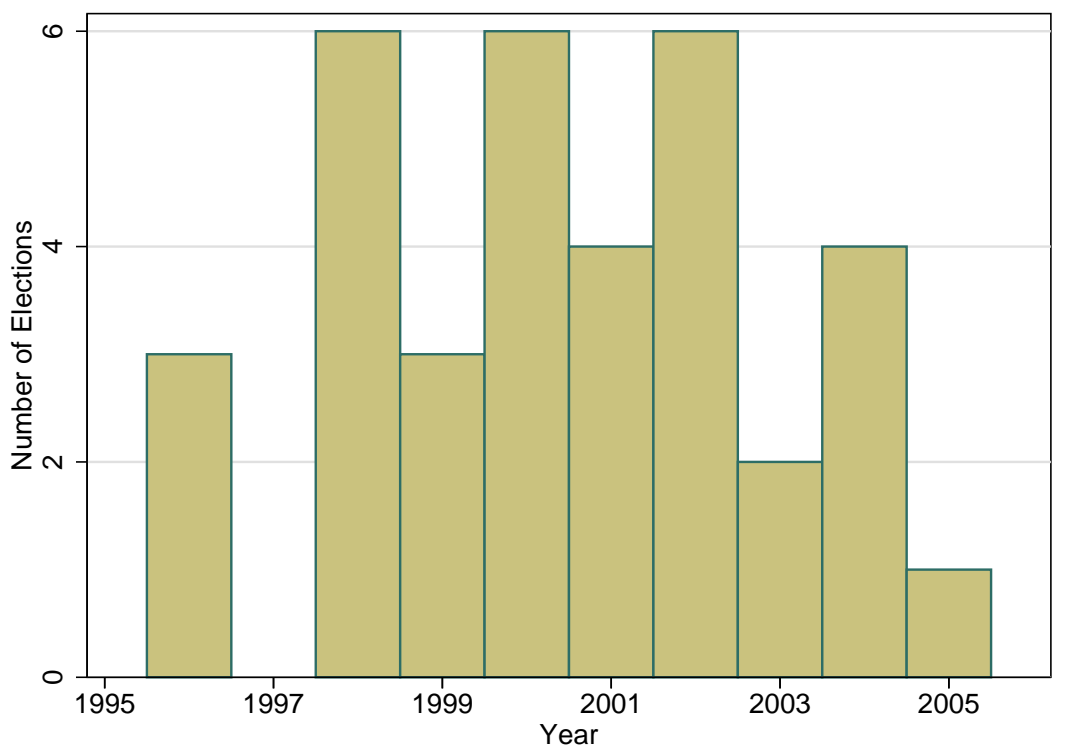

Figure A2: Distribution of Union Elections by Vote Share

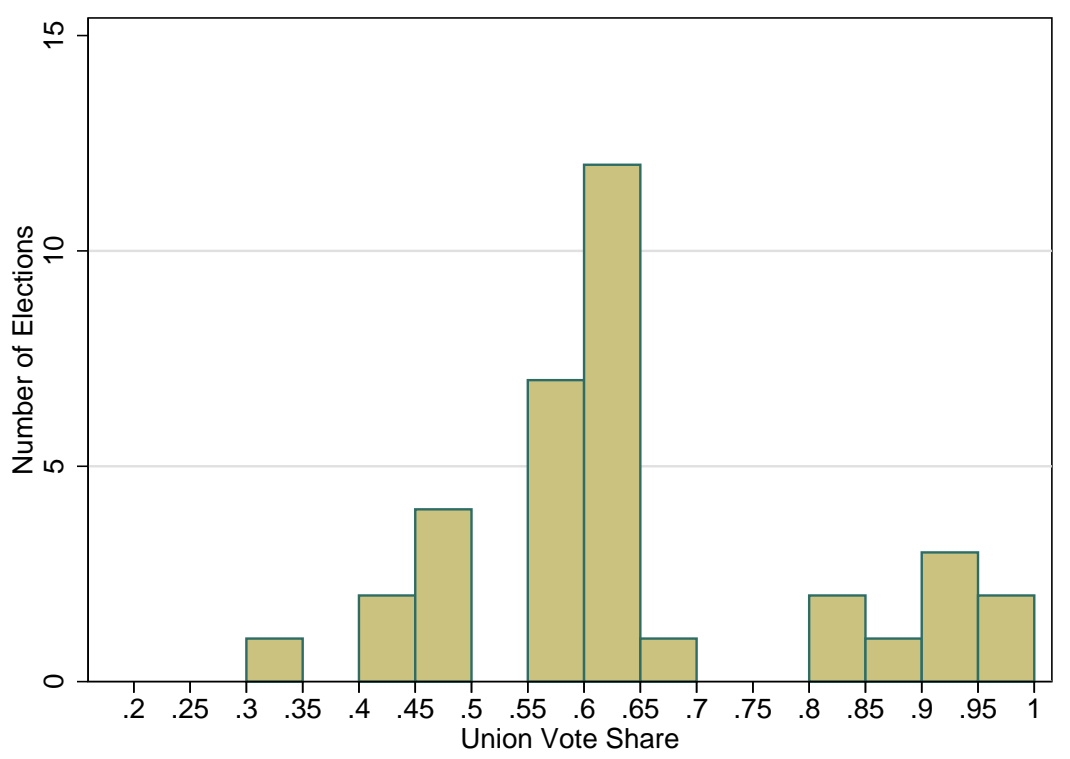

